\title{
Frequencies of genetic polymorphisms related to triptans metabolism in chronic migraine
}

\author{
Giovanna Gentile • Serena Missori • \\ Marina Borro • Alisa Sebastianelli • \\ Maurizio Simmaco $\cdot$ Paolo Martelletti
}

Received: 2 January 2010/Accepted: 16 February 2010/Published online: 6 March 2010

(C) Springer-Verlag 2010

\begin{abstract}
Chronic migraine (CM) prevalence ranges around $1-5 \%$. Most of these patients usually treat their acute attacks with triptans, whose efficacy is extremely variable. A genetic basis for migraine is evident and many susceptibility genes have been described, as well as gene polymorphisms possibly implied in therapy response. Several factors could be involved in the evolution of episodic migraine into a chronic form, such as natural history, psychiatric comorbidity, and the individual's response to therapy. During a study aimed at detecting connections between genotype and response to triptans administration, we characterized a $\mathrm{CM}$ population for polymorphisms in the genes coding for monoamine oxidase A, g-protein beta 3 and the cytochromes CYP3A4 and CYP1A2. Alleles and genotypes distributions were compared with known frequencies of healthy Caucasian populations. A significant association with $\mathrm{CM}$ was found for the long allele of monoamine oxidase A $30 \mathrm{bp}$ VNTR and CYP1A2*1F variant. Such genomic analysis is part of an integrated platform able to evaluate different levels of metabolic pathways of drugs in $\mathrm{CM}$ and their influence in the chronicization process.
\end{abstract}

G. Gentile · M. Borro · M. Simmaco

Department of Biochemical Sciences, Advanced Molecular Diagnostic Unit, 2nd School of Medicine, Sapienza University, Sant'Andrea Hospital, Via di Grottarossa 1035,

00189 Rome, Italy

S. Missori · A. Sebastianelli · P. Martelletti $(\varangle)$ Department of Medical and Molecular Sciences, Regional Referral Headache Center, 2nd School of Medicine, Sapienza University, Sant'Andrea Hospital, Via di Grottarossa 1035, 00189 Rome, Italy

e-mail: paolo.martelletti@uniroma1.it
Keywords Chronic migraine - Triptans · Pyrosequencing · Pharmacogenomics · Genetic liability

\section{Introduction}

The definition of chronic migraine (CM) is still debated $[1,2]$, although its prevalence ranges around $1-5 \%$ [3] and its management requires specific skills, being headaches that are most difficult to treat.

Triptans are mainly used for the acute treatment of CM attacks and share a similar mechanism of action, based on the stimulation of serotonin receptors $\left(5 \mathrm{HT}_{1 \mathrm{~B} / 1 \mathrm{D}}\right)$, yet their therapeutic benefits are largely variable among different subjects. Different metabolic rates may probably account for different levels of drug response. Enzymes belonging to the cytochrome P450 superfamily are the central metabolizer of eletriptan, frovatriptan and naratriptan, while the monoamine oxidase MAO A is the main metabolizing enzyme for sumatriptan and rizatriptan. The two systems cooperate in metabolism of almotriptan (MAO A and CYP 3A4) and zolmitriptan (MAO A, CYP 1A2 and CYP3A4) [4]. Several SNPs in these genes are related to alteration of enzymatic activity and genotypization can thus contribute to select the most adequate class of triptan to be administered.

Polymorphisms in genes involved in transduction signal via the $5 \mathrm{HT}_{1 \mathrm{~B} / 1 \mathrm{D}}$ receptor, as the C825T SNP in the gene coding the $\mathrm{G}$ protein $\beta 3$ subunit (GNB3), can also be important determinants of triptan therapy outcome [5].

In the framework of a study aimed at identifying a correlation between triptans response and individual genetic profile, we characterized a panel of gene SNPs involved in triptans pharmacokinetics and pharmacodynamics in a CM population. 


\section{Patients and methods}

Description of analyzed populations

A total of 104 patients (12 males 92 females) affected with CM, aged 25-81, were enrolled in the study. All patients were referred to the Regional Referral Headache Centre of 2nd School of Medicine of Sapienza University at Sant'Andrea Hospital in Rome, Italy. The diagnosis of CM was performed accordingly to 2006 ICHD-II revised rules [1]. The study received the approval of the University Ethic Committee. All patients signed a written consent before the enrolment in the study.

Genetic analysis

We studied the following DNA polymorphisms: an untranslated variable number of tandem repeats (uVNTR) of 30 basepairs located about $1.1 \mathrm{~kb}$ upstream of the ATG initiation codon of monoamine oxidase A (MAO A) gene; a $\mathrm{A} \rightarrow \mathrm{C}$ substitution and at position -163 and a $\mathrm{G} \rightarrow \mathrm{A}$ transition at position -3860 in the 5 'noncoding region of the CYP1A2 gene, indicated as $* 1 \mathrm{~F}$ allele (rs762551) and $* 1 \mathrm{C}$ allele (rs2069514), respectively; an A $\rightarrow \mathrm{G}$ transition at position -392 in the promoter region of CYP3A4 gene, indicated as $* 1 \mathrm{~B}$ allele ( $\mathrm{rs} 2740574)$ and a $\mathrm{C} \rightarrow \mathrm{T}$ transition at nucleotide 825 (rs5443) in the coding sequence of $\mathrm{G}$ protein $\beta 3$ subunit (GNB3) gene which produces a truncated form of the protein.

Genomic DNA was isolated from peripheral blood using the X-tractor Gene system (Corbett Life Science, Australia).

The MAO A promoter region polymorphism was genotyped on the basis of previously described method [6]. Identification of the amplified fragments size was performed by microchannel electrophoresis on chip, using the Agilent 2100 Bioanalyzer system (Agilent Technologies, Santa Clara, CA, USA).

All the single nucleotide polymorphisms were genotyped by pyrosequencing technology (Pyrosequencer PyroMark ID system-Biotage AB and Biosystems, Uppsala, Sweden). Forward, reverse and sequencing primers were obtained by PSQ Assay Design software (Biotage AB and Biosystems, Uppsala, Sweden). PCR primer pairs and sequencing primer for each SNP are reported in Table 1.
Briefly, regions covering the SNP of interest were amplified as follows: after initial denaturation $\left(95^{\circ} \mathrm{C}\right.$, $10 \mathrm{~min}$ ), a thermal cycler protocol ( 35 cycles) was employed cycling $20 \mathrm{~s}$ at $95^{\circ} \mathrm{C}, 20 \mathrm{~s}$ at $48^{\circ} \mathrm{C}$, followed by $30 \mathrm{~s}$ extension at $72^{\circ} \mathrm{C}$; a final extension of $5 \mathrm{~min}$ at $72^{\circ} \mathrm{C}$ was added. All PCR reactions were performed in a final volume of $50 \mu \mathrm{l}$ containing $40 \mathrm{ng}$ of genomic DNA, 10 pmol of each primer, $0.2 \mathrm{mM}$ dNTPs, the appropriate concentration of $\mathrm{MgCl}_{2}$ (Table 1), PCR buffer and $1 \mathrm{U}$ of Taq DNA polymerase (Takara Bio Inc., Otsu, Japan).

Single-stranded DNA was isolated from the PCR reaction using the Pyrosequencing Vacuum Prep Workstation (Biotage) and Streptavidin Sepharose TM High Performance beads (Amersham Biosciences, Uppsala, Sweden) that bind to the biotinylated primer. After washing in $70 \%$ ethanol, incubation in denaturing buffer and flushing with wash buffer, the beads were then released into a 96-well plate containing annealing buffer and the specific sequencing primer. Annealing was performed at $80^{\circ} \mathrm{C}$ for 2 min followed by cooling at room temperature. Then realtime sequencing was performed.

Statistical analysis

Chi-square Hardy-Weinberg equilibrium (HWE) test calculator for biallelic markers available at http://www.oege. org/software/hwe-mr-calc.shtml [7] was used to test for deviations of genotype frequencies from HWE. The genotype and allelic distributions in the migraine population were compared with those reported in literature for healthy Caucasian subjects.

In the case of the X-linked MAO A uVNTR polymorphism, male patients (12 out of 104 total subjects) were excluded from statistical analysis.

Genotypic and allelic frequencies among the different groups were compared using Chi-square analysis. Values of $P<0.05$ were considered significant.

\section{Results}

All the polymorphisms analyzed were in Hardy-Weinberg equilibrium. Frequencies of GNB3 C825T, CYP3A4*1B and CYP1A2*1C SNPs in CM population do not differ

Table 1 Primers and $\mathrm{Mg}^{2+}$ concentrations for PCR amplification and pyrosequencing

\begin{tabular}{lllll}
\hline SNPs & Forward primer $\left(5^{\prime}-3^{\prime}\right)$ & Reverse primer $\left(5^{\prime}-3^{\prime}\right)$ & Sequencing primer $\left(5^{\prime}-3^{\prime}\right)$ & $\mathrm{Mg}^{2+}$ concentration $(\mathrm{mM})$ \\
\hline CYP1A2*1C & CTTCTTGGATGCTTATGA & ${ }^{\text {a }}$ TGTAATTCCAGCTACTCG & ACCGCAACCTCCGCC & 1 \\
CYP1A2*1F & ${ }^{a}$ AGTGGAAACTGAGATGAT & ATACCAGAAAGACTAAGC & CTACCATGCGTCCTG & 1 \\
CYP3A4*1B & GGGATGAATTTCAAGTAT & ${ }^{a}$ GGGTTCTTATCAGAAACT & CAGCCATAGAGACAAGG & 1 \\
GNB3 C825T & ACGAGAGCATCATCTG & ${ }^{a}$ ATGGAGTCCCAGACAT & ATCTGCGGCATCACG & 1.5
\end{tabular}

${ }^{a}$ Biotin molecule attached 
from those reported in literature for healthy Caucasian subjects [8-10]. Pertaining to GNB3 C825T SNP, there are $50(48 \%)$ homozygous noncarriers of the mutated $825 \mathrm{~T}$ allele, $42(40.4 \%)$ heterozygous carriers and $12(11.5 \%)$ homozygous carriers of the mutated $825 \mathrm{~T}$ allele in our study population.

As regards CYP3A4 $-392 \mathrm{~A}>\mathrm{G}$ SNP, only $4(3.8 \%)$ heterozygous carriers of the mutated $\mathrm{G}$ allele were found; the remaining $100 \mathrm{CM}$ patients $(96.2 \%)$ were homozygous noncarriers of the mutated variant. About CYP1A2, there are $99(95.2 \%)$ homozygous noncarriers of $* 1 \mathrm{C}$ allele and 5 $(4.8 \%)$ heterozygous carriers of the mutated $-3860 \mathrm{~A}$ allele.

Concerning the MAO A uVNTR polymorphism, the 3R, $4 \mathrm{R}$ and $5 \mathrm{R}$ genetic variants are present in our population. The $3 R$ and $4 R$ alleles account for the $98 \%$ of the total, according to literature reports [11] but their frequencies are significantly different in our migraine population compared with the Italian healthy population previously reported [3]. The $3 \mathrm{R}$ variant is under-represented (29.8 vs. $42.2 \%)$ and the $4 \mathrm{R}$ variant is over-represented (67.9 vs. $55 \%)$ in $\mathrm{CM}$ as reported in Table 2.

A significant difference in frequency distributions was also found for the CYP1A2*1F. In detail, the CYP1A2*1F allele is over-represented in CM (47.1 vs. $31 \%)$. There are $34(32.7 \%)$ homozygous noncarriers of the mutated $-163 \mathrm{C}$ allele, $42(40.4 \%)$ heterozygous carriers and $28(26.9 \%)$ homozygous carriers of the mutated $-163 \mathrm{C}$ allele (Table 3).

\section{Discussion}

We designed a study to characterize potential association between genotype and triptans response in $\mathrm{CM}$, aimed to assign a targeted therapy according to the metabolic class (based on genotype) of the CM patients. Here, we present the results of the preliminary genetic characterization of a population of $104 \mathrm{CM}$ patients.

Genotyping of single nucleotide polymorphisms was performed by pyrosequencing technology, a modern platform able to provide fast, accurate and reliable qualitative sequencing data simultaneously with quantitative allele frequency information, for up to 96 samples in one step. Genotyping for CYP1A21F is reported in Fig. 1.

On the basis of our analysis, neither GNB3 and CYP3A4 SNPs nor CYP1A $2 * 1 \mathrm{C}$ variant seems to be implicated in the genetic liability to $\mathrm{CM}$, whereas an association was found for MAO A and CYP1A2*1F polymorphisms.

Monoamine oxidase $\mathrm{A}$ is the metabolic enzyme of neurotransmitters and the UVNTR polymorphism located in its promoter affects its transcriptional activity modulating the levels of monoamines. In detail, enzyme expression is relatively high for carriers of 3.5 or 4 repeats (MAO
Table 2 Allelic frequencies of MAO A uVNTR polymorphism in controls (Data from Deckert et al. [6]) and chronic migraine

$d f$ degrees of freedom

${ }^{a}$ Data from Deckert et al. [6]

Table 3 Genotypic and allelic frequencies of CYP1A2

$-163 \mathrm{~A}>\mathrm{C}$ SNP in controls (Data from Skarke et al. [20]) and chronic migraine

\begin{tabular}{|c|c|c|c|}
\hline $\begin{array}{l}\text { Mao A uVNTR } \\
\text { alleles }\end{array}$ & $\begin{array}{l}\text { Migraine female patients } \\
(n=92) \\
n(\%)\end{array}$ & $\begin{array}{l}\text { Healthy female subjects }{ }^{\mathrm{a}} \\
(n=70) \\
n(\%)\end{array}$ & $\chi^{2}(p)$ \\
\hline $2 \mathrm{R}$ & 0 & $2(1.4)$ & $\begin{array}{c}8.39(0.039) \\
d f=3\end{array}$ \\
\hline $3 R$ & $55(29.9)$ & $59(42.2)$ & \\
\hline $4 \mathrm{R}$ & $125(67.9)$ & 77 (55) & \\
\hline $5 \mathrm{R}$ & $4(2.2)$ & $2(1.4)$ & \\
\hline
\end{tabular}

\begin{tabular}{llll}
\hline $\begin{array}{l}-163 \mathrm{~A}>\mathrm{C} \\
(\mathrm{CYP} 1 \mathrm{~A} 2 * 1 \mathrm{~F})\end{array}$ & $\begin{array}{l}\text { Migraine patients } \\
\left(\begin{array}{l}n=104) \\
n(\%)\end{array}\right.\end{array}$ & $\begin{array}{l}\text { Healthy subjects }_{(n=495)}^{\mathrm{a}} \\
n(\%)\end{array}$ & $\chi^{2}(p)$ \\
\hline $\begin{array}{l}\text { Genotype } \\
\text { CC }\end{array}$ & $28(26.9)$ & $44(8.9)$ & $27(<0.00001)$ \\
CA & $42(40.4)$ & $227(45.9)$ & $d f=2$ \\
AA & $34(32.7)$ & $224(45.2)$ & \\
Alleles & $98(47.1)$ & $315(31)$ & $17.8(<0.00001)$ \\
C & & & $d f=1$ \\
\end{tabular}



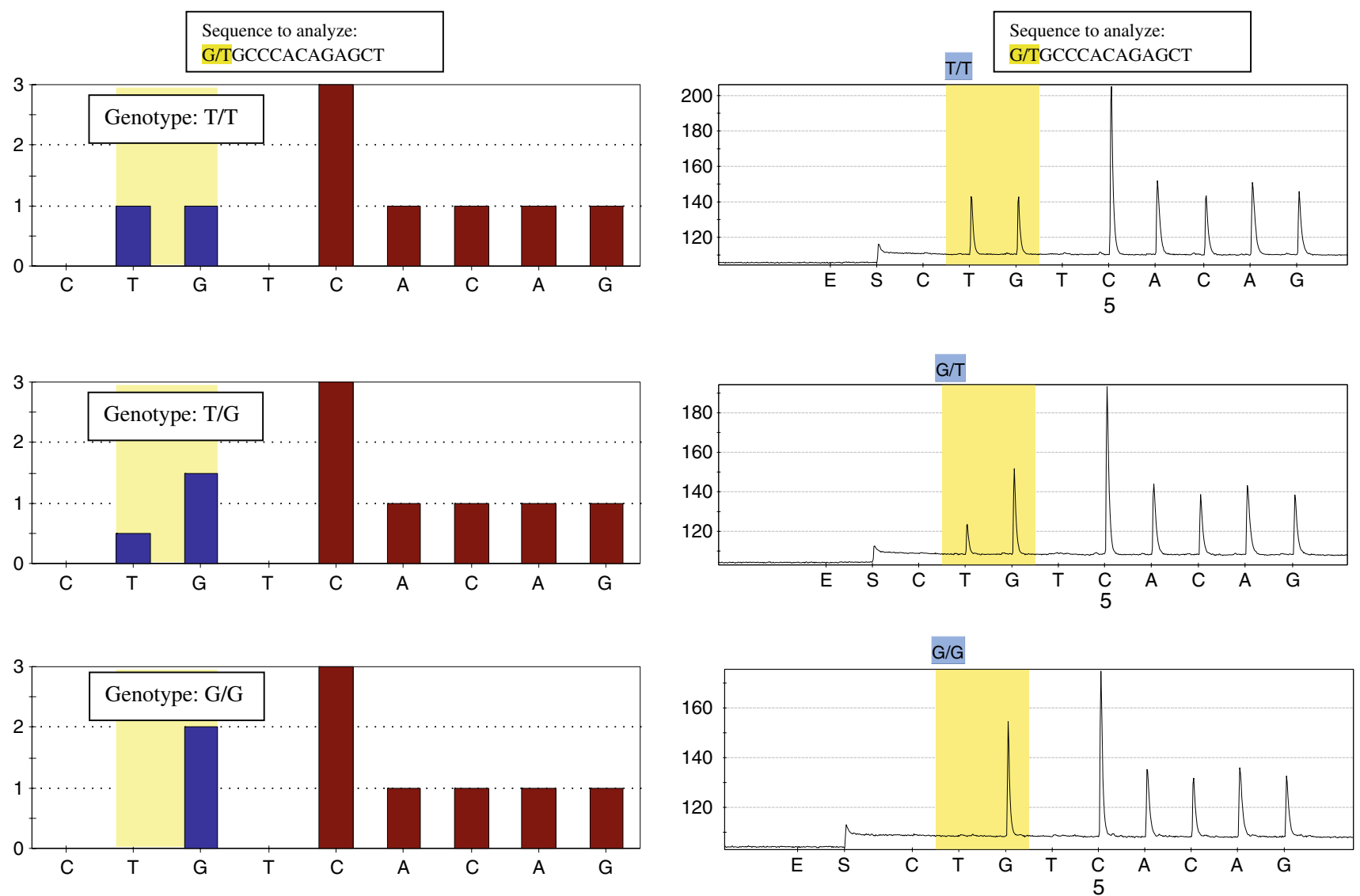

Fig. 1 Genotyping of CYP1A2*1F by pyrosequencing technology based on the sequencing-by-synthesis method. The sequence of interest is analyzed by the instrument which produces a graphic (pyrogram) reporting the nucleotides inserted in the fragment of DNA

A-high) and lower for carriers of 2, 3, or 5 repeats (MAO A-low) [9, 12]. To better discriminate $15-30$ bp length differences, PCR fragments' size was determined by the Bioanalyzer platform, a more sensitive and accurate method than the classical agarose/acrylamide gel electrophoresis (Fig. 2). Our data indicate an over-representation of the MAO A-high form in migraineurs. The functional effect of this variant is an increased MAO A activity which, leading to hypermetabolism of amine neurotransmitters, might cause a lower level of serotonin, a condition often described in association with migraine pathophysiology [13].

The cytochrome P450 enzyme CYP1A2 plays a main role in the metabolism of a variety of structurally unrelated compounds, including a broad range of different drugs and its activity is widely modulated by a plethora of inducer/ inhibitor molecules. As the other members of the cytochrome P450 superfamily, CYP1A2 gene is highly polymorphic and the $* 1 \mathrm{C}$ and the $* 1 \mathrm{~F}$ alleles are associated with reduced metabolic activity $[14,15]$. We found a significant over-representation of the $* 1 \mathrm{~F}$ variant in migraineurs. An involvement of $* 1 \mathrm{~F}$ allele has been described in

synthesized. Reverse-complement sequence has been analyzed. Theoretical pyrograms are reported (left panel). The observed sequences are shown in the right. Region including the SNP of interest is highlighted in yellow

various unrelated pathologies $[16,17]$ and its effect on the enzymatic activity and inducibility of cytochrome has been mainly studied in relation with smoking, a main known inducer of cytochrome.

A more comprehensive analysis is required to elucidate the effective functional link between $* 1 \mathrm{~F}$ variant and migraine, taking into account physiological, environmental and lifestyle factors affecting both CYP P450 phenotype and the manifestation of migraine pain.

The potential of MAO A and CYP 1A2 polymorphisms as susceptibility factors for migraine should be further addressed in light of the known implication of these genes in metabolism of triptans, especially in the case of zolmitriptan, which undergoes a two-step catabolism: an active metabolite is produced by CYP1A2 (more stable and active of the parent compound) and successively degraded by the MAO A activity [18]. Therefore, the study of functional interaction between CYP and MAO A SNPs might be of striking impact for tailored drug selection [19]. The possibility to define a specific metabolic background responsible for drug's efficacy (triptans) in migraine could reduce 
Fig. 2 Comparison between classic agarose gel electrophoresis and chip technology for resolution and accuracy. The same samples were analyzed by electrophoresis onto $3 \%$ agarose gel (a) and Bioanalyzer 2100 (b). The molecular weight of the upper band in the S1 line of the agarose gel is not unambiguously assignable. b Gel-like image and electropherograms of samples S1 and S2 obtained by Bioanalyzer 2100 analysis. The exact length of the longer fragment is easily determined ( $M k$ molecular weight marker)
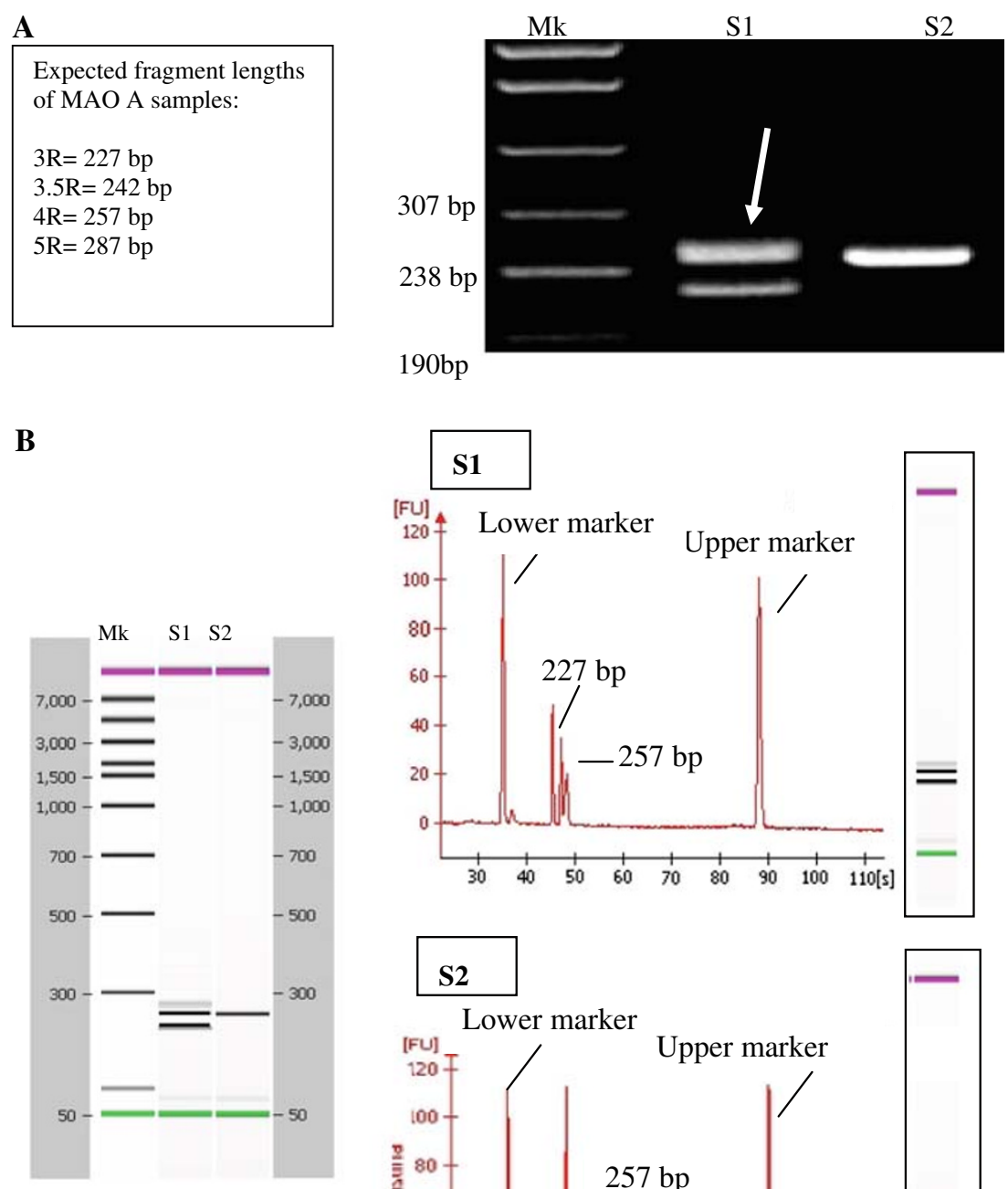
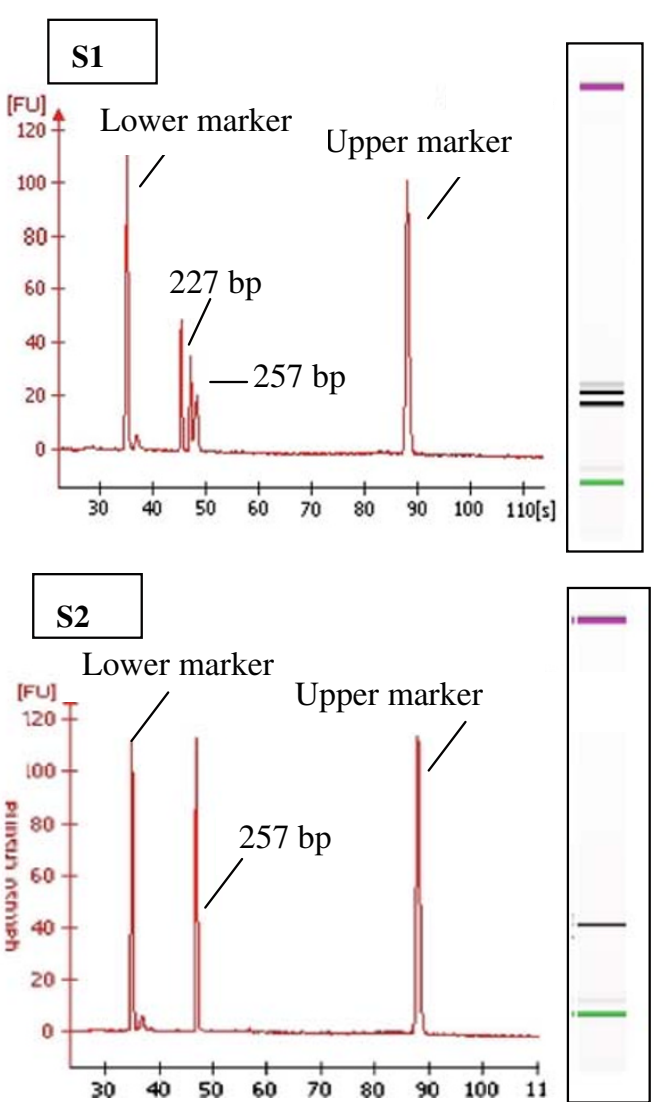

the use (misuse $\rightarrow$ abuse) of such drugs in a pre-defined nonresponders' population of migraine patients, avoiding one of the most important factors in the chronicization progress towards $\mathrm{CM}$, such as triptans abuse. The next steps in the research area of CM determinants should include pharmacogenomics for the definition of the responders' patients to specific known drugs, such as triptans [20-22] as well as the application of these methods in testing new active compounds for migraine [23, 24].

Conflict of interest None.

\section{References}

1. Headache Classification Committee, Olesen J, M-G- Bousser, Diener HC, Dodick D, First M, Goadsby PJ, Göbel H, Lainez
MJA, Lance JW, Lipton RB, Nappi G, Sakai F, Schoenen J, Silberstein SD, Steiner TJ (2006) New appendix criteria open for a broader concept of chronic migraine. Cephalalgia 26:742-746

2. Manack A, Turkel C, Silberstein S (2009) The evolution of chronic migraine: classification and nomenclature. Headache 49:1206-1213

3. Natoli JL, Manack A, Dean B, Butler Q, Turkel CC, Stovner L, Lipton RB (2009) Global prevalence of chronic migraine: a systematic review. Cephalalagia. doi:10.1111/j.1468-2982.2009. 01941.x

4. Ferrari A, Sternieri E, Ferraris E, Bertolini A (2003) Emerging problems in the pharmacology of migraine: interactions between triptans and drugs for prophylaxis. Pharmacol Res 48:1-9

5. Schürks M, Kurth T, Stude P, Rimmbach C, de Jesus J, Jonjic M, Diener HC, Rosskopf D (2007) G protein beta3 polymorphism and triptan response in cluster headache. Clin Pharmacol Ther 82:396-401

6. Deckert J, Catalano M, Syagailo YV, Bosi M, Okladnova O, Di Bella D, Nöthen MM, Maffei P, Franke P, Fritze J, Maier W, Propping P, Beckmann H, Bellodi L, Lesch KP (1999) Excess of 
high activity monoamine oxidase A gene promoter alleles in female patients with panic disorder. Hum Mol Genet 8:621-624

7. Rodriguez S, Gaunt TR, Day INM (2009) Hardy-Weinberg equilibrium testing of biological ascertainment for Mendelian randomization studies. Am J Epidemiol. doi:10.1093/aje/kwn359

8. Thibaudin L, Berthoux P, Thibaudin D, Mariat C, Berthoux F (2004) G protein beta3 subunit C825T polymorphism in primary IgA nephropathy. Kidney Int 66:322-328

9. Garsa AA, McLeod HL, Marsh S (2005) CYP3A4 and CYP3A5 genotyping by Pyrosequencing. BMC Med Genet 9;6:19

10. Pavanello S, Pulliero A, Lupi S, Gregorio P, Clonfero E (2005) Influence of the genetic polymorphism in the $5^{\prime}$-noncoding region of the CYP1A2 gene on CYP1A2 phenotype and urinary mutagenicity in smokers. Mutat Res 587:59-66

11. Filic V, Vladic A, Stefulj J, Cicin-Sain L, Balija M, Sucic Z, Jernej B (2005) Monoamine oxidases A and B gene polymorphisms in migraine patients. J Neurol Sci 228:149-153

12. Sabol SZ, Hu S, Hamer D (1998) A functional polymorphism in the monoamine oxidase A gene promoter. Hum Genet 103:273279

13. Panconesi A (2008) Serotonin and migraine: a reconsideration of the central theory. J Headache Pain 9:267-276

14. Sachse C, Brockmoller J, Bauer S, Roots I (1999) Functional significance of a $\mathrm{C} \rightarrow \mathrm{A}$ polymorphism in intron 1 of the cytochrome P450 CYP1A2 gene tested with caffeine. Br J Clin Pharmacol 47:445-449

15. Nakajima M, Yokoi T, Mizutani T, Kinoshita M, Funayama M, Kamataki T (1999) Genetic polymorphism in the 5'-flanking region of human CYP1A2 gene: effect on the CYP1A2 inducibility in humans. J Biochem Tokyo 125:803-808
16. Goodman MT, McDuffie K, Kolonel LN, Terada K, Donlon TA, Wilkens LR, Guo C, Le Marchand L (2001) Case-control study of ovarian cancer and polymorphisms in genes involved in catecholestrogen formation and metabolism. Cancer Epidemiol Biomarkers Prev 10:209-216

17. Cornelis MC, El-Sohemy A, Campos H (2004) Genetic polymorphism of CYP1A2 increases the risk of myocardial infarction. J Med Genet 41:758-762

18. Basile VS, Ozdemir V, Masellis M, Walker ML, Meltzer HY, Lieberman JA, Potkin SG, Alva G, Kalow W, Macciardi FM, Kennedy JL (2000) A functional polymorphism of the cytochrome P450 1A2 (CYP1A2) gene: association with tardive dyskinesia in schizophrenia. Mol Psychiatry 5:410-417

19. Rapoport AM, Tepper SJ, Sheftell FD, Kung E, Bigal ME (2006) Which triptan for which patient? Neurol Sci 27(Suppl 2):S123S129

20. Skarke C, Kirchhof A, Geisslinger G, Lötsch J (2005) Rapid genotyping for relevant CYP1A2 alleles by pyrosequencing. Eur J Clin Pharmacol 61:887-892

21. Simmaco M, Borro M, Missori S, Martelletti P (2009) Pharmacogenomics in migraine: catching biomarkers for a predictable disease control. Expert Rev Neurother 9:1267-1269

22. Asuni C, Cherchi A, Congiu D, Piccardi MP, Del Zompo M, Stochino ME (2007) Association study between clinical response to rizatriptan and some candidate genes. J Headache Pain 8:185189

23. Farinelli I, De Filippis S, Coloprisco G, Missori S, Martelletti P (2009) Future drugs for migraine. Inter Emerg Med 4:367-373

24. Stovner L, Tronvik E, Hagen K (2009) New drugs for migraine. J Headache Pain 10:395-406 